\title{
IGF-II ameliorates the dystrophic phenotype and coordinately down-regulates programmed cell death
}

\author{
J Smith ${ }^{\star, 1}$, C Goldsmith ${ }^{1}$, A Ward ${ }^{2}$ and R LeDieu ${ }^{1}$ \\ ${ }^{1}$ School of Biosciences, University of Birmingham, Edgbaston, Birmingham \\ B15 2TT, UK \\ 2 School of Biology and Biochemistry, University of Bath, Bath BA2 7AY, UK \\ * Corresponding author: J Smith, School of Biosciences, University of \\ Birmingham, Edgbaston, Birmingham B15 2TT, UK. Tel: +(44) 1214145408 \\ Fax: +(44) 870 169-7117; E-mail: J.Smith.20@bham.ac.uk
}

Received 16.3.00; revised 21.6.00; accepted 3.7.00

Edited by RA Knight

\begin{abstract}
Duchenne muscular dystrophy (DMD) is a fatal and crippling disease of skeletal muscle which displays increased fibre turnover and elevated levels of programmed cell death (PCD) in muscle stem cells. Previously we showed that this cell death is inhibited by the growth factor IGF-II. To determine the functional significance of PCD to the dystrophic phenotype, we used a transgene to over-express IGF-II in the $\mathrm{mdx}$ mouse. We found that ectopic expression of IGF-II inhibited the elevated PCD observed in skeletal muscles in the absence of functional dystrophin and significantly ameliorates the early gross histopathological changes in skeletal muscles characteristic of the dystrophic phenotype. Replacement of the dystrophin gene abolished abnormal skeletal muscle cell PCD levels in vivo in a dose-dependent manner and in dystrophic SMS cell lines cultured in vitro. Thus elevation of stem cell PCD in dystrophic skeletal muscle is a direct consequence of the loss of functional dystrophin. Together these data demonstrate that elevated skeletal muscle cell PCD is a critical component of dystrophic pathology and is inversely correlated with both dystrophin gene dosage and with muscle fibre pathology. Targeting PCD in dystrophic muscles reduces both PCD and the classical features of dystrophic pathology in the $m d x$ mouse suggesting that IGF-II is a strong candidate for therapeutic intervention in the dystrophinopathies. Cell Death and Differentiation (2000) 7, 1109-1118.
\end{abstract}

Keywords: programmed cell death; apoptosis; mdx; muscular dystrophy; survival factor; IGF-II

Abbreviations: DMD, Duchenne muscular dystrophy; PCD, programmed cell death; IGF-II, insulin-like growth factor two; SMS, skeletal muscle stem (cell); DAG, dystrophin associated glycoprotein; GH, growth hormone; DIG, digoxygenin; PBS, phosphate buffered saline

\section{Introduction}

Duchenne Muscular dystrophy (DMD), is a debilitating heritable disease of skeletal muscle ${ }^{1}$ caused by the absence of functional dystrophin protein, ${ }^{2}$ due to mutation of the dystrophin gene which is located on the short arm (Xp21) of the X-chromosome. ${ }^{3}$ The role of dystrophin in the physiology of muscle cells remains unclear although its location near the sarcolemma ${ }^{4}$ and formation of a transmembrane complex with the dystrophin associated glycoproteins (DAGs) ${ }^{5}$ and syntrophins ${ }^{6,7}$ suggests that it may have a signalling function. ${ }^{8}$ However, the size and location of this complex is also consistent with dystrophin being structural in function. ${ }^{2}$ When dystrophin is absent or abnormal, as in the case of DMD or $m d x$, the mouse dystrophic model, ${ }^{9,10}$ the entire complex is absent ${ }^{11}$ resulting in severe disruption of normal skeletal muscle function and loss of muscle stability. This results in cycles of fibre degeneration followed by bouts of regeneration. ${ }^{12}$ Loss of other members of the complex such as laminin$2 /$ merosin $^{7}$ also results in a similar dystrophic phenotype. This initial phase of the disease is characterised by an increase in both proliferation and PCD of skeletal muscle stem (SMS) or satellite cells ${ }^{13}$ and is followed by a progressive crippling fibrosis in both $\mathrm{DMD}^{1}$ and, to a lesser extent, $m d x^{14}$ skeletal muscles. It is this end point of the pathology of DMD that contributes most to the severe disability and early death suffered by DMD patients. The mechanism by which this fibrosis develops is unknown but is likely to involve the inappropriate expression of muscle growth factors in a process analogous to that found in wound healing. ${ }^{15}$

Skeletal muscle apoptosis was first demonstrated by electron microscopy in the muscles of children with acute infantile spinal muscular atrophy. ${ }^{16}$ Elevated PCD levels were then reported in the skeletal muscles of dystrophic $(m d x)$ mice by ourselves ${ }^{13,17,18}$ and by several other groups. ${ }^{19,20}$ More recently, elevated PCD has been shown to be a general feature of the dystrophic phenotype and has been reported in the muscle cells of children with limb girdle muscular dystrophy, ${ }^{21}$ myotonic dystrophy ${ }^{22}$ and Merosin (dy/dy), ${ }^{23} \gamma$-sarcoglycan ${ }^{24}$ and $\alpha$-5-integrin ${ }^{25}$ deficient dystrophic mouse muscles. In $m d x$ at least, it is clear that PCD is primarily elevated in the satellite or stem cells of dystrophic muscles. ${ }^{13,19}$ Elevated PCD seems to extend throughout the life ${ }^{18}$ of these mice although absolute levels decline significantly following the most active phase of the disease in mice at around 3 months of age. However the greatest discrepancy between normal and dystrophic skeletal muscle cell apoptosis levels occurs at the time (2-5 weeks), just prior to and including the juvenile period of upregulated cycling of $m d x$ muscle fibres, when the most overt dystrophic histopathology is observed in $m d x$ skeletal muscles. This period lasts until the animals are approxi- 
mately 8 weeks of age and involves massive muscle fibre degeneration and regeneration accompanied by increased serum levels of muscle creatine kinases ${ }^{10}$ indicating severe muscle fibre breakdown. These data suggest that apoptosis and PCD contribute to dystrophic pathology and confirm an earlier report ${ }^{19}$ that apoptosis precedes necrosis in these muscles. Consistent with the subsequent recovery of $m d x$ skeletal muscle pathology, the levels of pyknosis (an indicator of PCD) can be observed to decline with age, ${ }^{18}$ but remain consistently elevated above the levels observed in normal muscle even in old age (18 months). To date the only reported survival factor for skeletal muscle cells is IGF${ } \mathrm{I}^{13}$ and there have now been several reports which suggest that IGF-II may have an anti-apoptotic role both in skeletal muscle cells ${ }^{13,26}$ and in other tissues. ${ }^{27,28}$

However none of these studies addresses the direct relationship between PCD and dystrophin, or between skeletal muscle cell death and the secretion of survival factors such as IGF-II. In order to examine the functional relationship between IGF-II and dystrophin we have made use of a transgenic mouse model (Blast) which overexpresses IGF-II. ${ }^{29}$

Rodent IGF-II levels normally become substantially reduced shortly following birth. ${ }^{30}$ Transgenic overexpression of IGF-II in the Blast $\left(\mathrm{aA}^{\mathrm{t}}\right)$ mouse $^{29}$ yields mice which have significantly elevated levels of IGF-II throughout their life. ${ }^{29,31}$ The lgf-2 transgene is expressed from a keratin (VI) promoter and these mice have ectopic IGF-II expression in their gut epithelium, uterine wall and in skin, all of these tissues exhibit an overgrowth phenotype. ${ }^{29}$ Plasma levels of the IGF-II related peptides; insulin, growth hormone $(\mathrm{GH})$ and IGF-I are not greatly altered in these mice, although levels of IGF-I are slightly lower than normal. $^{31}$ In this study we have examined the long-term effect of elevated serum IGF-II peptide on $m d x$ muscle by cross breeding the $m d x$ mouse with Blast $\left(\mathrm{aA}^{\mathrm{t}}\right)$ mice.

\section{Results}

\section{mdx $x$ Blast F1 cross and control animals}

Juvenile (4-6 weeks old) $m d x\left(x^{d} x^{d}\right)$ female mice were mated in a $1: 1$ natural mating protocol with one of four male Blast $\left(a A^{t}\right)$ studs (Figure 1a). A total of 16 litters were born and designated TM $1 a-d$ to TM $7 a-d$. Tail samples were taken for determination of genotype. To avoid observer bias the results of the tail identification were held until after PCD had been assessed in the animals skeletal muscles. Control F1 litters (TC) were established between juvenile female C57B1 mice and the same Blast $\left(a A^{t}\right)$ studs used to generate the TM litters. Twenty-nine mice from four TC litters were generated and genotype determined from tail biopsies as before. Four backcross (BC) litters (30 animals) were generated by crossing $m d x$ Blast $\left(x^{d} Y, a A^{t}\right)$ males to $m d x\left(x^{d} x^{d}\right)$ females (Figure 1b). Blast $\left(x^{d} Y, a A^{t} ; x^{d} X, a A^{t}\right.$ and $\left.x^{d} x^{d}, a A^{t}\right)$ juvenile animals born from TM, BC and TC crosses appeared healthy and displayed no gross abnormalities other than those previously described for Blast. Thus by 5-6 weeks Blast $\left(x^{d} Y, a A^{t} ; x^{d} X, a A^{t}\right.$ and $\left.x^{d} x^{d}, a A^{t}\right)$ animals had begun to display wrinkly skin, occasional prolapsed colons and reduced fat
A: F1 Cross

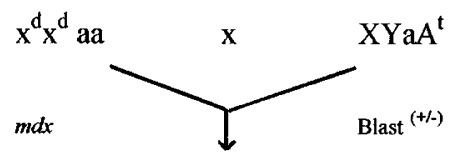

(1) TM

$X x^{d}$ aa $(25 \%), \quad x^{d} Y$ aa $(25 \%)$

(2) $\mathrm{TM}^{+}(m d x$ Blast $)$

$X x^{d} a A^{t}(25 \%), x^{d} Y$ aAt $(25 \%)$

carrier female dystrophic male

B: Backcross (BC)

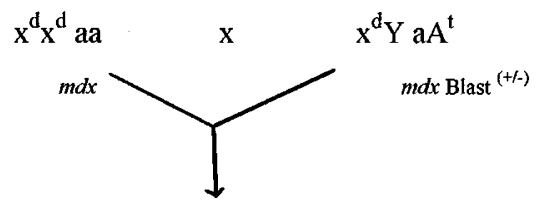

(1) $\mathrm{BC}^{-} \quad \mathrm{x}^{\mathrm{d}} \mathrm{X}^{\mathrm{d}} \mathrm{aa}, \mathrm{x}^{\mathrm{d}} \mathrm{Y}$ aa (dystrophic)

(2) $\mathrm{BC}^{+} \quad \mathrm{x}^{d} \mathrm{x}^{d} \mathrm{aA}^{\mathrm{t}}, \mathrm{x}^{\mathrm{d}} \mathrm{Y} \mathrm{aA}^{\mathrm{t}}$ (mdx transgene)

C: Control FI cross

as for $\mathbf{A}$ using $\mathrm{C} 57 \mathrm{~B} / 10$ females in place of $\mathrm{C} 57 \mathrm{~B} / 10 \mathrm{mdx}$ females

(1) $\mathrm{TC}^{-} \quad \mathrm{XY}$ aa, $\mathrm{XX}$ aa

(2) $\mathrm{TC}^{+} \quad \mathrm{XY} \mathrm{aA}{ }^{\mathrm{t}}, \mathrm{XX} \mathrm{aA}^{\mathrm{t}}$ (transgene)

Figure 1 Genetic crosses were as follows: (a) F1 cross between $m d x$ females (C57Black/10 background) and Blast males (CBA background) carrying the Igf-2 transgene heterozygously $\left(\mathrm{aA}^{\mathrm{t}}\right)$ results in $\mathrm{TM}$ litters with four expected genotypes at a ratio of $1: 1: 1: 1$. The sex ratio should be evenly split between female carrier $\left(x^{d} X\right)$ and male dystrophic $\left(x^{d} Y\right)$ animals and half of each of these groups will carry the lgf-2 transgene $\left(x^{d} X a A^{t}\right.$ and $\left.x^{d} Y a A^{t}\right)$ and half should not ( $x^{d} X$ aa and $x^{d} Y$ aa). (b) Control F1 cross between C57Black/ 10 females and Blast males (CBA background) carrying the lgf-2 transgene heterozygously $\left(\mathrm{aA}^{\mathrm{t}}\right)$ results in $\mathrm{TC}$ litters with expected genotypes at a ratio of $1: 1$. Male and female ratios should be even, half will carry the lgf-2 transgene ( $X X$ a $A^{t}$ and $X Y$ a $A^{t}$ ) and half should not ( $X X$ aa and $X Y$ aa). (c) Backcross between $m d x$ females (C57Black/10 background) and transgene positive $F 1$ TM males (CBA $\times$ C57Black/10 background) should yield male and female dystrophic animals in equal ratio, half will carry the Igf-2 transgene $\left(x^{d} x^{d} a A^{t}\right)$ and half will not $\left(x^{d} x^{d} a a\right)$

deposits beneath the skin. An excess of male to female liveborn animals was observed in MM, TM and BC litters but not in TC and CC litters. This however only reached statistical significance (by Chi squared analysis) in the TM litters $(P<0.01)$. The Blast $\left(\mathrm{aA}^{\mathrm{t}}\right)$ transgene was evenly distributed between male and female mice and did not deviate from the expected 1:1 ratio in either TM, TC or BC litters. These figures also include five animals (all female) which died perinatally in TM litters. No further deaths were observed in TM litters over the first 12 months of life. With the exception of $m d x$ litters (MM) where mean litter size was significantly reduced ( $\chi^{2}$ analysis; $P<0.01$ ), the litter sizes of all crosses were comparable. 


\section{IGF-II expression in $\mathbf{m d x B l a s t}$ transgene positive mice}

IGF-II expression in $m d x B$ last transgene positive mice was determined by in situ hybridisation of paraffin embedded late gestation (E18.5) embryo sections (Figure $3 b-d$ ). As expected ectopic expression of IGF-II was found in the suprabasal (keratinous) layer of the dermis and in the gut epithelium (Figure $3 b, d$ ) of $m d x$ Blast transgene positive embryos but not of $m d x$ Blast transgene negative embryos (Figure 3a). Endogenous expression of IGF-II was also observed in these embryos at all expected sites including liver, skeletal muscle, chondrocytes (Figure 3c,d) choroid plexus and palate (not shown). Specificity of the transcribed probe to IGF-II was confirmed by competition with unlabelled

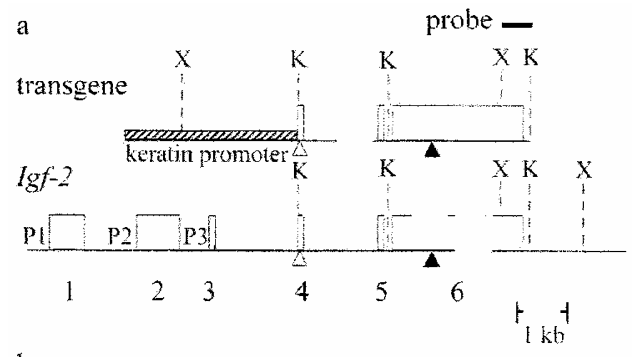

b

T NT

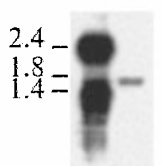

Figure 2 (a) The stucture of the Igf-2 gene (Rotwein and Hall, 1990) is shown below the BKVI: Igf-2 transgene. ${ }^{25}$ Exons (open boxes) are numbered 1-6 and the positions of translation start (open triangles) and stop (closed triangles) codons are indicated, as well as sites for $K p n l(K)$ and $X$ bal $(X)$. Three promoters from Igf-2 are indicated (P1-P3), as is the keratin promoter (shaded box), and the region used as a probe in Southern blots (thick horizontal line). All distances are approximate. (b) A representative Southern blot, used to detect the presence of BKVI:Igf-2, is shown. One transgenic (T) and one non-transgenic sample (NT) are shown, after digestion of DNA with $X b a l$. The approximate sizes of three major bands detected by an Igf-2 exon 6 probe are given (in $\mathrm{kb}$ ). That of $1.8 \mathrm{~kb}$ derives from the endogenous Igf-2 gene and is present in all samples. Other bands are transgene-specific and their greater intensity reflects multiple transgene copies integrated in a single array (fragments of $2.4 \mathrm{~kb}$ occur at each tail:head junction and $1.4 \mathrm{~kb}$ at each tail:tail junction) probe. Adult ectopic expression of IGF-II was also confirmed by immunohistochemistry (data not shown). As expected we observed no ectopic expression of IGF-II in the muscles of Igf2 transgenic mice.

\section{Amelioration of dystrophic skeletal muscle pathology in Igf-2 transgene carrying mice}

In order to carry out a detailed controlled study of the IGF-II (Blast transgene) effect on the dystrophic phenotype we backcrossed male $m d x$ Blast $\left(x^{d} Y, a A^{t}\right)$ mice from the $F 1$ progeny of the TM series onto female $m d x$ mice. The resulting litters $(B C)$ comprised close to the expected $1: 1$ ratio of Blast positive $\left(x^{d} Y, a A^{t}\right.$ and $\left.x^{d} x^{d}, a A^{t}\right)$ to Blast negative $\left(x^{d} Y\right.$, aa and $x^{d} x^{d}$, aa) with a slight excess of animals not carrying the transgene (Table 1). Animals were sacrificed at 5 weeks post birth to coincide with the onset of active dystrophic phenotype. Dystrophic phenotype of skeletal muscles was assessed by examination of haemotoxylin and eosin stained paraffin wax

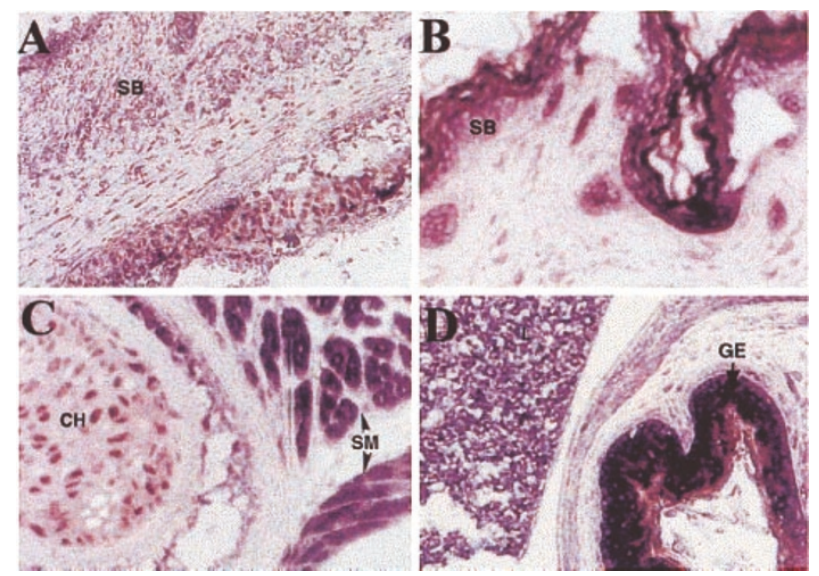

Figure 3 DIG mRNA in situ hybridisation using an Igf-2 riboprobe transcribed using T7 RNA polymerase from the p28a-mouse lgf-2 gene. This probe detects endogenous IGF-II expression in transgene negative $\left(\mathrm{TM}^{-}\right)$late gestation (E 18.5) embryos (a) and both endogenous and ectopic (transgene driven) IGF-II expression in transgene positive $\left(\mathrm{TM}^{+}\right)$late gestation (E 18.5) embryos $(\mathbf{b}-\mathbf{d})$. Endogenous expression of IGF-II is seen $(\mathbf{a}, \mathbf{b})$ in hair follicles $(F)$, in $(\mathbf{a}, \mathbf{c})$ skeletal muscle $(S M),(\mathbf{c})$ in chondrocytes $(\mathrm{CH})$ and $(\mathbf{d})$ in liver $(L)$. Ectopic expression of IGF-II is observed strongly in (B) the suprabasal layer $(S B)$ of the skin and (d) in the gut epithelium (GE). Sections are not counterstained

Table 1 Animal breeding statistics

\begin{tabular}{lcccccccc}
\hline Cross & Litters & $\begin{array}{c}\text { Total } \\
\text { animals }\end{array}$ & $\begin{array}{c}\text { Animals } \\
\text { used }\end{array}$ & Male & Female & $\begin{array}{c}\text { Mean } \\
\text { litter size }\end{array}$ & Tblast $^{+}$ & Tblast $^{-}$ \\
\hline TM & 16 & 131 & 113 & $79^{\star}$ & 34 & 8.2 & 60 & 53 \\
TC & 4 & 29 & 25 & 14 & 11 & 7.3 & 13 & 12 \\
BC & 4 & 30 & 30 & 19 & 11 & 7.5 & 11 & 19 \\
MM & 15 & 70 & 67 & 43 & 29 & 4.8 & - & -17 \\
CC & 4 & 38 & 29 & 15 & 14 & 9.5 & - & 29 \\
\hline
\end{tabular}

Animals used in this study were derived by cross breeding $m d x(\mathrm{MM})$ or normal congenic C57BI mice $(\mathrm{CC})$ with $\mathrm{CBA}$ males heterozygous $(+/-)$ for the lgf-2 transgene (Blast). The resulting F1 litters from these crosses (TM and TC litters respectively) were analysed together with $m d x(\mathrm{MM})$ and control (CC) litters. Backcross litters (BC) were generated by crossing $m d x$ females with transgene positive (+l-) TM males. Genotype transmission was roughly as expected in all crosses with the exception of sex ratio which was skewed significantly in TM litters in favour of male animals. A slight excess of males was also observed in the $m d x$ (MM) litters suggesting that it is the dystrophin defect which is responsible for the loss of female progeny. *Statistically significant excess of males, $P<0.01$ by $\chi^{2}$ analysis 
sections cut transversely (t/s) through BC lower limb skeletal muscle (Figure 4). Abnormalities of skeletal muscle typical of the dystrophic phenotype were observed in both Blast $\left(x^{d} Y\right.$, $a A^{t}$ and $\left.x^{d} x^{d}, a A^{t}\right)$ positive (Figure $\left.4 b\right)$ and Blast $\left(x^{d} Y\right.$, aa and $x^{d} x^{d}$, aa) negative animals but were considerably reduced in all of the transgene positive Blast animals (Figure 4d) which displayed less uneveness in fibre size and appeared to have fewer areas of degeneration, regeneration and developing fibrosis than siblings not carrying the transgene. Muscles from transgene negative mice were indistinguishable from those of $m d x$ dystrophic controls (Figure 4c), whilst the histology of the muscles of the transgene positive mice was much closer to that seen in normal (C57B1/10) muscles (Figure 4a). However there was some variation in phenotype within the BC muscles and in order to confirm our observations we chose to quantify three key parameters of dystrophy in these muscles; per cent central nuclei, cellularity, and incidence of fibrosis and degenerative regions. In all of the dystrophic parameters quantified, except for fibrosis, we observed a statistically significant reduction (Table 2 ) in the muscles of $\mathrm{BC}$ animals carrying the lgf-2 transgene $\left(\mathrm{BC}^{+}\right)$.

The observed decrease in regenerating fibres in $\mathrm{BC}^{+}$ compared to $\mathrm{BC}^{-}$animals was found to be statistically significant both when total central nuclei (C) were compared between the two groups and when the per cent of centrally nucleated fibres (100C/F) was compared, with $P$ values of less than $5 \%$ and less than $2 \%$ respectively. The observed decreases in fibre number and in muscle cellularity observed in $\mathrm{BC}^{+}$animals were not found to be statistically significant at the $5 \%$ level. This may be because fibrotic/degenerating areas in the $\mathrm{BC}^{+}$muscles were generally smaller in area and more scattered throughout the muscle (see Figure 4b). No differences

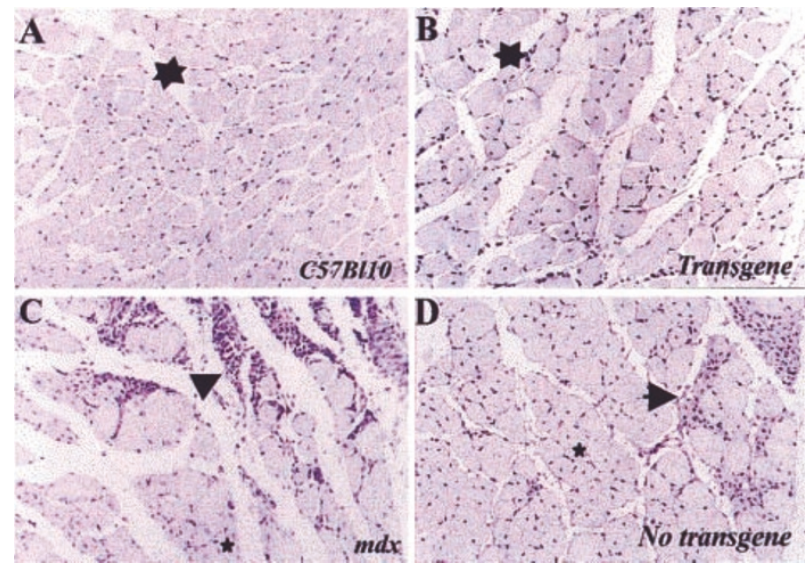

Figure 4 Comparison between normal 5-week-old lower limb muscles from C57B1/10 mice (a), those from dystrophic $(m d x)$ mice (c) and dystrophic mice with (b) and without the Igf-2 transgene (d). Skeletal muscles from dystrophic $(m d x)$ and transgene negative $\left(\mathrm{BC}^{-}\right)$mice displayed characteristic dystrophic histology with areas of gross histopathology (arrows), cell infiltration, incipient fibrosis, irregular fibre sizes and increased numbers of small centrally nucleated (regenerating) muscle fibres (indicated with a star). These features were much reduced $(\mathbf{b})$ in the muscles of animals carrying the transgene $\left(\mathrm{BC}^{+}\right)$ and are absent (a) in non-dystrophic control animals. In contrast muscle fibres are evenly sized and nuclei are predominantly peripheral in both normal (a) and transgene carrying (b) mice were observed between male and female animals (data not shown).

\section{Dystrophin gene dosage effect on skeletal muscle programmed cell death}

We used propidum iodide to examine the extent of PCD in the skeletal muscles of 5-week-old $m d x \times$ Blast F1 litters (TM) and compared these with the progeny of a C57B1 $x$ Blast cross (TC litters). Analysis of results (Figure $5 \mathrm{a}$ ) showed that levels of PCD in the control (TC) cross did not vary between male and female mice or between mice which did and did not carry the transgene and were consistently low (approximately $2 \%$ of total cells counted). In contrast however, we observed that the level of PCD in animals of the TM cross was greatest (Figure $5 a)$ in TM ( $x^{d} Y$, aa) males, was reduced in TM males carrying the transgene $\left(x^{d} Y, a A^{t}\right)$ and further reduced in TM carrier females $\left(x^{d} X\right.$, aa and $\left.x^{d} X, a A^{t}\right)$ whether or not they carried the transgene, suggesting that reintroduction of the dystrophin gene was inhibiting PCD. A decrease in PCD was observed both when TM $\left(x^{d} Y, a A^{t}\right)$ males were compared to TM $\left(x^{d} Y\right.$, aa) males and when female transgene positive animals $\left(X^{d} X\right.$, $\left.a A^{t}\right)$ were compared to siblings not carrying the transgene $\left(x^{d} X, a a\right)$. This suggested that ectopic expression of IGF-II was further reducing $P C D$ in the muscles of transgene carrying animals. This effect of IGF-II was however only statistically significant $(P<0.05$, Student's $t$-test) in male $\mathrm{F} 1$ mice. The lack of a statistically significant difference between female transgenic mice and their female siblings could be explained by the fact that the female F1 mice were heterozygous for the dystrophin lesion and so were carriers of the disease rather than dystrophic. The female sibling controls therefore (as described above) had lower levels of PCD in their muscles than the males had. Thus larger numbers of female mice than males would probably be required to demonstrate a significant difference between transgenic and non-transgenic mice. In order to further investigate, the effect of the transgene alone we therefore eliminated the carrier effect by backcrossing F1 $m d x$ Blast $\left(x^{d} Y, a A^{t}\right)$ males onto $m d x$ females, producing litters, which were entirely dystrophic.

Table 2 The effect of the Igf-2 transgene on dystrophic phenotype in BC litters

\begin{tabular}{lcccc}
\hline & $\begin{array}{c}\text { Transgene } \\
(+)\end{array}$ & $\begin{array}{c}\text { Transgene } \\
(-)\end{array}$ & t-value & $\begin{array}{c}\text { Probability } \\
(\boldsymbol{P})\end{array}$ \\
\hline Fibres (F) & $144+9.59$ & $159.9+11.66$ & 1.65 & $<0.20$ \\
Central nuclei & $65.55+6.19$ & $81.42+9.20$ & 2.56 & $<0.05^{\star}$ \\
$\quad(\mathrm{C})$ & & & & \\
C/F (\%) & $44.82+2.72$ & $52.60+2.86$ & 2.86 & $<0.02^{\star *}$ \\
Cellularity & $342.95+21$ & $375.19+24.45$ & 1.54 & $<0.20$ \\
Degenerative & $26.87+2.91$ & $24.08+2.41$ & 0.96 & $<0.40$ \\
$\quad$ and fibrotic & & & & \\
$\quad(\%)$ & & & & \\
\hline
\end{tabular}

Dystrophic phenotype was characterised using the following parameters: regeneration was assessed by comparing the ratio $(C / F)$ between centrally nucleated fibres $(C)$ and total fibre number $(F)$ and was found to be significantly reduced in transgene positive animals; $\left(^{*}\right) P<0.02$ and $\left(^{* *}\right) P<0.05$ by Student's $t$-test. The levels of fibrosis and degeneration were not significantly different between transgene positive and negative animals at 5 weeks of age 


\section{Ectopic expression of IGF-II inhibits PCD in dystrophic mice}

We have further investigated the effect of IGF-II transgene expression of skeletal muscle apoptosis by backcrossing $m d x$ Blast $\left(x^{d} Y, a A^{t}\right)$ mice onto female $m d x$ mice producing mice with a more uniform (C57B1) genetic background (BC litters),

(a)

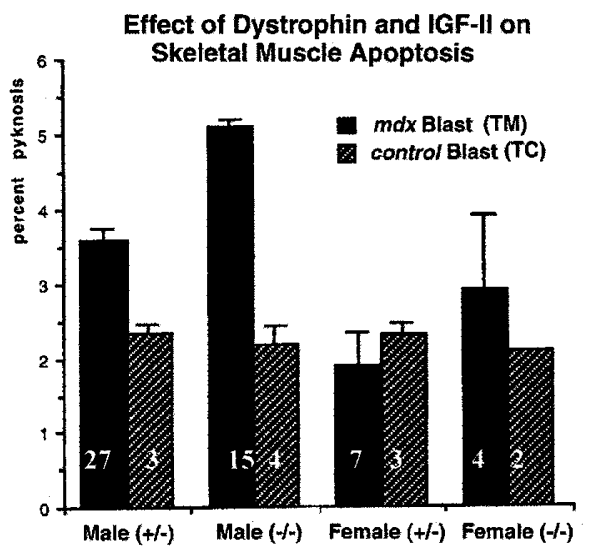

(b)

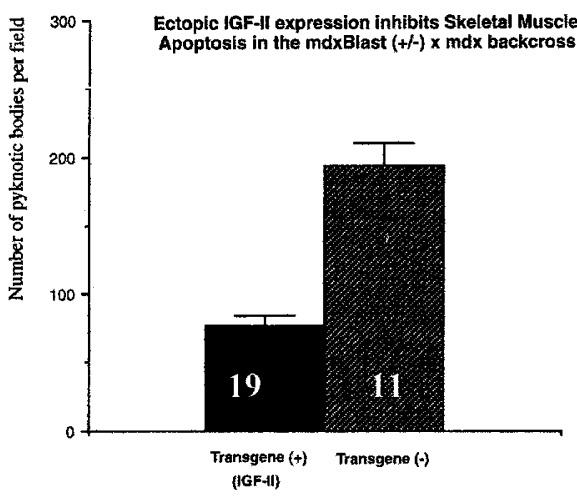

Figure 5 Programmed cell death (PCD) was determined in the muscles of 5 week-old animals from TM, BC and TC litters (described in Figure 2), using propidium iodide as described. ${ }^{13}$ (a) The F1 crosses: as expected all control (TC) animals have low levels $(<2 \%)$ of PCD in their muscles regardless of gender or presence of the Igf-2 transgene. In the muscles of animals from the dystrophic F1 cross (TM), however, variable levels of cell death were observed. PCD was significantly elevated in the muscles of male animals compared to their female siblings, demonstrating the carrier effect in females, which carry one functional dystrophin allele. A further reduction of PCD levels was observed in muscles of animals carrying the lgf-2 transgene $(+/-)$ compared to those which did not $(-/-)$ and this difference was significant in males. Data are expressed as mean per cent pyknotic cells of total counted. Error bars indicate 1 standard deviation. The numbers in each bar indicate the number of mice assayed in each category $(n)$. (b) None of the backcrossed $(B C)$ animals have a functional dystrophin gene and consequently they have elevated PCD levels. However PCD is significantly reduced in the muscles of those animals carrying the lgf-2 transgene (+) compared to their siblings which do not (Transgene $(-))$. Data are expressed as mean \pm standard deviation of pyknotic bodies per field. Each field is the area $\left(0.063 \mathrm{~mm}^{2}\right)$ covered by a $10 \times 10$ grid at $\times 40$ magnification. The numbers in each bar indicate the number of mice assayed in each category $(n)$ and enabling comparison of the effects of the Blast gene in both male and female dystrophic mice. We used two separate detection methods (acridine orange and propidium iodide) to confirm that PCD of these 5-week-old BC mice was significantly reduced by $62 \%$ when the Blast Igf- 2 transgene was present $\left(\mathrm{BC}^{+}\right)$compared to animals which did not $(\mathrm{BC})$ carry the transgene (Figure $5 \mathrm{~b}$ ). This result is highly statistically significant (Student's $t$-test; $P<0.001$ ).

\section{Dystrophin minigene abolishes PCD in dystrophic cell lines}

We further tested the functional relationship between dystrophin and PCD by transient transfection of a dystrophin gene construct (pBSX-mda) into the $m d x$ derived skeletal muscle stem cell line dfd13 (Figure 6). Cells which were mock transfected with saline or which were transfected with the $\beta$ galactosidase gene or (in later experiments) with the GFP gene, retained high levels of PCD as measured by TUNEL labelling, whilst PCD was almost completely abolished in those cells into which the dystrophin gene was transfected even though transfection rates were less than $20 \%$ of the cell population. Identical transfection experiments in which acridine orange or propidium iodide were used to determine cell death, reproducibly gave the same result. Transfection rate was estimated by assessing $\beta$-galactosidase or GFP positive cells/dish and found to be between 9 and $17 \%$. Transfection of dfd13 cells with dystrophin did not increase differentiation of these cultures during the time span of the experiment $(24-36 \mathrm{~h})$ as determined by incidence of myoblast fusion; i.e. no myotubes were observed in any of the experimental or control dishes during the course of these experiments.

These data suggest that dystrophin plays an important role in the control of skeletal muscle cell apoptosis and that this role is likely to be mediated by the secretion of a diffusible molecule such as a growth factor. We tested this

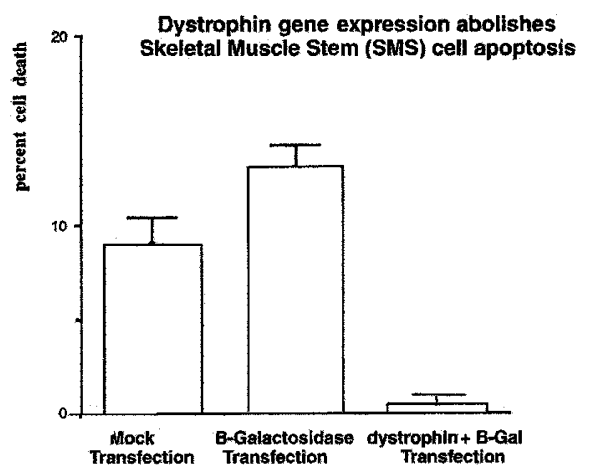

Figure 6 Skeletal muscle stem (SMS) cells derived from $m d x$ mouse muscles have elevated levels of PCD. ${ }^{13}$ Transient transfection of the $m d x$ derived SMS cell line dfd1.3 with a construct (pBSX-mda) containing the dystrophin gene reproducibly abolishes $P C D$ in this cell line. The figure is a representative experiment demonstrating this observation, in which dystrophin was cotransfected with a $\beta$-galactosidase construct (EF-NLS-lacZ) to monitor transfection rates. Two control transfections with saline carrier alone (mock transfection) and with the $\beta$-galactosidase gene alone did not have this effect. Data is presented as mean + standard deviation 
possibility by transferring conditioned medium (CM) from transfected to non-transfected dystrophic cells (Table 3) and assaying for pyknotic cell death. Total cell number was slightly higher in cells treated with $\mathrm{CM}$ from dystrophin transfected cells, both when transfected with dystrophin alone and with dystrophin and GFP, compared to CM from mock transfected cells or those transfected with GFP alone (Table 3a). This increase, although not statistically significant is likely to reflect the observed survival effect. When per cent pyknosis in cells incubated with CM taken from cells transfected with dystrophin was compared to cells incubated with $\mathrm{CM}$ from cells not transfected with dystrophin there was a statistically significant reduction in PCD (Table 3b). These results show clearly that dystrophin transfected cells, but not those transfected with a control gene (GFP) or mock transfected, secrete a signal which inhibits pyknotic cell death in dystrophic cells.

\section{Discussion}

Skeletal muscle dystrophy is primarily a disease of dysfunctional regulation of skeletal muscle growth so that both regeneration and degeneration processes are upregulated during the active phase of the disease. In the dystrophic $(m d x)$ mouse this active phase has its onset in the juvenile animal between 4 and 8 weeks post birth. Previously we have shown ${ }^{18}$ that this is also the period during which the greatest rate of programmed cell death (PCD) occurs in the stem cells of these muscles. It is this part of the disease process which is thought to stimulate the progressive features of the disease, the increasing inability to repair degenerating muscle regions and the consequent increase in fibrosis. ${ }^{2}$ The mechanism by which this process occurs is yet to be uncovered, however, implicit in the finding that muscle stem cells (which themselves don't express dystrophin) die at greater rates in dystrophic muscles, is the existence of signalling molecules (such as growth factors) which instruct

Table 3 Conditioned medium from dystrophin transfected cells inhibits PCD

\begin{tabular}{lcccc}
\hline (a) & Mock & GFP & Dys & GFP+Dys \\
\hline $\begin{array}{c}\text { Total cells } \\
(x \pm \text { SD })\end{array}$ & $760 \pm 90$ & $1047 \pm 75$ & $1451 \pm 190$ & $1092 \pm 180$ \\
$\begin{array}{c}\text { Pyknotic cells } \\
(x \pm \text { SD })\end{array}$ & $28.5 \pm 11$ & $55 \pm 4$ & $16 \pm 4$ & $5 \pm 0$ \\
\hline
\end{tabular}

(b)

\begin{tabular}{lc}
\hline Conditioned medium & Per cent pyknosis (\%) \\
\hline - Dystrophin & $5.0 \pm 0.64$ \\
+ Dystrophin & $0.8 \pm 0.38^{*}$ \\
\hline
\end{tabular}

(a) Table shows the mean and standard deviation of data obtained from two separate transfection experiments where conditioned medium (CM) was removed following transfection and placed onto non-transfected dystrophic cells (dfd13) at a density of $10^{4}$ cells $/ \mathrm{cm}$. Cell nuclei were stained with DAPI to reveal pyknotic cells. (b) Effects of transfecting dystrophin (Dystrophia alone+Dystrophia and GFP) on the anti-apoptotic effect of CM, compared with CM from control cells (Mock transfected and CMV GFP) which were not transfected with dystrophin Expressed as per cent pyknosis of total. *Statistically significant $(P>0.005)$ by $\chi^{2}$ analysis these cells on whether to live or die. ${ }^{13}$ In skeletal muscles one of these molecules appears to be IGF-II. In this paper we show two lines of evidence to support the conclusion that skeletal muscle PCD is dependent on extrinsic factors whose expression is dependent on the ability to express dystrophin. The first is that ectopic expression of the diffusible peptide IGF-II can inhibit PCD in dystrophic muscles and the second is that when dystrophin expression is forced in a fraction of cultured skeletal muscle cells a very strong survival effect is observed on the whole cell population. Furthermore transfer of the conditioned medium secreted by these transfected cells to non-transfected cells also significantly reduced dystrophic muscle cell death.

\section{Up-regulation of Igf-2 ameliorates the dystrophic phenotype}

In this paper we have used the Igf-2 transgenic mouse line Blast $(+/-)$ to demonstrate that exposure of dystrophic skeletal muscles to IGF-II can ameliorate the phenotype of these muscles. A striking effect of ectopic Igf-2 expression on dystrophic muscles was observed in 5-week-old $m d x$ animals during the active phase of the disease. In animals carrying the Igf-2 transgene we observed a strong reduction in both PCD and fibre regeneration suggesting that circulating IGF-II may be slowing the upregulated turnover seen in dystrophic muscles. The reduction of muscle fibre regeneration, shown by a reduction in the number of centrally located nuclei in skeletal muscle fibres in a muscle, is a good indicator of amelioration of the dystrophic phenotype. ${ }^{32,33}$ The finding that both stem cell death and fibre regeneration were reduced by IGF-II in the muscles of $m d x$ Blast $(+/-)$ transgenic mice, suggests that, in common with many other systems, these two processes are coupled in skeletal muscle. In skeletal muscle several lines of evidence suggest that this may be the case. Cell cycle control in skeletal muscle is intimately linked with terminal differentiation via the negative growth regulator/ tumour suppressor Rb1 (retinoblastoma) gene. ${ }^{34}$ Mice deficient for the Rb1 gene normally die during gestation at $\mathrm{E} 14.5$, however by partial rescue of the null $\mathrm{Rb}(-/-)$ mutant, it has been shown ${ }^{35}$ that reduced expression of $\mathrm{Rb} 1$ leads to both upregulated myoblast apoptosis (PCD) and to a failure of surviving differentiated myotubes to form fully mature myofibres suggesting that $\mathrm{Rb} 1$ is required for both of these processes.

\section{Dystrophin inhibits PCD of muscle cells}

We have shown that skeletal muscle cell PCD can be functionally associated with the expression of the dystrophin gene in mature muscles suggesting that increased skeletal muscle cell PCD is indeed a feature of the skeletal muscle dystrophies and a consequence of the loss of functional dystrophin. In the muscles of female carriers we found levels of PCD which were intermediate between those seen in normal and dystrophic skeletal muscles. This finding is consistent with previous studies on human carriers of the disease $^{36}$ who, although free of clinical symptoms of DMD, often have elevated serum levels of muscle-specific enzymes indicating an upregulation of muscle cycling. This dose- 
dependent up-regulation of muscle stem cell PCD in muscles with no $\left(x^{d} x^{d}\right.$ or $\left.x^{d} Y\right)$ or reduced $\left(x^{d} X\right)$ levels of dystrophin and the inhibition of PCD in cultured cells transfected with dystrophin could be explained in several different ways. It is possible that very low levels of dystrophin exist in these cells, although this has never been detected by sensitive RT-PCR methods. Another, more likely possibility is that these cells are maintained by survival factors emitted by normal mature muscle fibres, in the same way that satellite stem cells respond to distant growth factor signalling from degenerating muscle fibres by migrating and proliferating to replace that fibre. Fibres with low levels or no dystrophin, particularly those which are regenerating or degenerating, may be unable to produce this signal efficiently. The existence of an endogenous growth factor survival signal is supported by our observation that cultured $m d x$ SMSc transfected with dystrophin exhibit a strong reduction in PCD even though less than a fifth of the cell population were expressing dystrophin. It has similarly been shown recently ${ }^{37}$ that motorneurone function is altered in muscular dystrophy, which must also be via an indirect mechanism in response to changes in the dystrophic muscle environment. Some of these changes are also likely to contribute to the elevation of skeletal muscle cell death. In particular it has been shown that perforin mediated cytotoxicity (generated by T-cells in dystrophic mouse muscle infiltrate) contributes to the induction of muscle cell death in these muscles. ${ }^{38}$ We have shown recently ${ }^{39}$ that two growth factors (FGF-1 and FGF-2) which are known to be elevated in dystrophic mouse muscles can induce skeletal muscle stem cell death. The further elucidation of these signalling molecules and their induction in dystrophic skeletal muscles therefore may have significant implications for the development of future treatment regimes for this class of diseases.

\section{Possible therapeutic approaches for DMD}

Therapeutic intervention in DMD is currently limited to the partially palliative procedures of surgical correction for spinal lordosis and the controversial use of prednisolone. ${ }^{40}$ It is estimated that, in order to effect a cure of dystrophic muscle using a gene therapy approach, between 20 and $50 \%$ of muscle fibres of all affected muscles must express dystrophin. ${ }^{41}$ Our data on $m d x$ in this paper is consistent with this conclusion. Currently replacement of up to $50 \%$ of skeletal muscle dystrophin in DMD patients is a technically insurmountable feat. Following a study ${ }^{42}$ in which mouse myoblasts were sucessfully reintroduced into the muscles of a dystrophic mouse model, several attempts ${ }^{43,44}$ to reproduce this procedure in human DMD patients have met with very limited success. One problem is that the majority of these clinical trials used primary cultured cells which are unpredictable in their incorporation rates, another is that it is difficult to achieve a sufficiently high incorporation rate to effect a change in the injected muscles in either human or mouse. An alternative cellular approach might be to employ cultured skeletal muscle stem cells (for discussion see ${ }^{45}$ ) carrying a diffusible gene product, such as a growth factor, able to effect a change over several muscle fibres.
In DMD all of the skeletal musculature, representing some $30 \%$ of the total body mass, is affected. This together with the fact that dystrophin is a cell autonomous protein, makes systemic delivery of a therapeutic gene an appropriate route ${ }^{46}$ for a gene therapy approach. Unfortunately there are currently no available gene delivery vectors which can specifically target skeletal muscle although recent work suggests that this may be done by attaching an artifical virus to a ligand such as transferrin which is strongly expressed in regenerating skeletal muscle cells. ${ }^{46}$ Another approach would be to incorporate a muscle specific promoter such as creatine kinase or troponin- $1^{47}$ into a viral vector which could then be administered systemically. Whether the delivery method is systemic or local, DMD presents particular problems for gene therapy because of the size $(2.6 \mathrm{Mb})$ of the dystrophin gene and of its mRNA $(14 \mathrm{~kb})$ which limits the choice of delivery vectors.

An alternative approach would be to identify another gene, which would be able to overcome the defect caused by the lack of dystrophin. One such candidate, which has been extensively characterised, is utrophin or dystrophinrelated protein-1 (DRP-1) which is encoded by an autosomally located gene with considerable sequence homology to the X-located dystrophin gene. ${ }^{48}$

An argument for this approach comes from work showing that ectopic expression of utrophin using the skeletal muscle specific promoter human $\alpha$-actin can ameliorate dystrophic phenotype in the skeletal muscles of the $m d x$ mouse. ${ }^{49}$ Recently it has been shown that a growth factor, heregulin, can up-regulate utrophin expression at the transcription level. ${ }^{50}$

We have identified another gene, IGF-II, which may also be able to circumvent the lesion in skeletal muscle caused by the absence of dystrophin by targeting the early histopathology of the disease and inhibiting the upregulated PCD observed in dystrophic muscles.

\section{Conclusion}

We have identified a growth factor, IGF-II, which may be of therapeutic use in the treatment of the muscular dystrophies. We showed that the upregulation of PCD was directly associated with the loss of a functional dystrophin gene and that ectopically expressed IGF-II improved the phenotype of $m d x$ mouse. In addition to its small size IGF-II has the advantage of being a diffusible protein and therefore may be more easily distributed to the skeletal muscle target than large membrane associated proteins such as dystrophin and utrophin.

\section{Materials and Methods}

\section{Animals and generation of transgenic crosses}

Homozygous C57B1 mdx ( $\left.x^{d} x^{d}\right)$ mice were generated from a nucleus of animals generously provided by the AFRC unit (Roslin, Edinburgh). lgf-2 Blast $\left(\mathrm{aA}^{\mathrm{t}}\right)$ animals were maintained as heterozygotes on a CBA background as previously described. ${ }^{29} m d x\left(x^{d} X\right)$ and $\left(x^{d} Y\right)$, Blast $\left(a A^{t}\right)$ F1 (TM) litters were generated by natural matings between 
juvenile C57B1 $m d x\left(x^{d} x^{d}\right)$ females and four tried and tested CBA Blast $\left(a A^{t}\right)$ male studs resulting in 32 litters and a total of $131 \mathrm{~F} 1$ mice. Four control (TC) F1 litters were also obtained by breeding Blast $\left(a A^{t}\right)$ studs with C57B1/10 juvenile females. Backcross mice were generated by crossing genotype confirmed male mdxBlast $\left(x^{d} Y, a A^{t}\right)$ studs (four in all) with juvenile C57B1 $m d x\left(x^{d} x^{d}\right)$ females resulting in four litters (see Table 1 for a summary of mice used). These crosses are summarised in Figure 1. Animals were sacrificed as E18.5 litters, and at 5 weeks post birth when overt dystrophic histopathology peaks in the muscles of $m d x$ mice.

\section{Preparation of muscle and embryo samples}

Animals for use in the study were heavily anaesthetised with Avertin $(0.4 \mathrm{ml} / 10 \mathrm{~g}$ body weight of freshly prepared $0.6 \%$ solution $2,2,2-$ tribromoethanol in 2-methyl-2-butanol) and fixed by cardiac perfusion as described previously. ${ }^{18}$ Briefly, following a cardiac injection of heparin $(0.1 \mathrm{ml}$, vetdrug), animals were exsanguinated by perfusion with a vascular saline rinse $(8 \mathrm{~g} / \mathrm{l} \mathrm{NaCl}, 0.25 \mathrm{~g} / \mathrm{l} \mathrm{KCl}, 0.05 \mathrm{~g} / \mathrm{l} \mathrm{CaCl}$, $0.5 \mathrm{~g} / \mathrm{l} \mathrm{NaHCO}_{3}, 0.05 \mathrm{M} \mathrm{NaHPO}_{4}: \mathrm{pH} 7.4$ ) via a butterfly needle inserted into the heart, followed by fixation by perfusion with $4 \%$ paraformaldehyde (in phosphate buffered saline). The perfusion step was necessary to eliminate blood cells which could otherwise generate false positives in PCD assays. Tibialis anterior muscles were dissected out and postfixed overnight in $4 \%$ paraformaldehyde followed either by (i) three changes over $12 \mathrm{~h}$ in $30 \%$ sucrose and cryopreservation in OCT compound (Miles) for the preparation of frozen muscle sections $(7 \mu \mathrm{m})$; or by (ii) careful dehydration followed by paraffin wax embedding for the preparation of wax sections. Embryos were dissected from the uterus of their mother, directly after she had been anaesthetised by avertin and then killed by cervical dislocation. Embryos were fixed in cold paraformaldehyde and processed for paraffin embedding as described above (orientation was either sagittal or transverse).

\section{Confirmation of genotype}

Derivation of four transgenic mouse lines with extra copies of the murine Igf-2 coding region under the control of the bovine keratin VI (BK VI; equivalent to human keratin 10) gene promoter was previously described. ${ }^{29}$ Briefly, the transgene construct comprises genomic fragments of approximately $4.5 \mathrm{~kb}$ from the BKVI gene, fused to a $5.0 \mathrm{~kb}$ region from Igf-2 (Figure $2 \mathrm{a}$ ). In this study we have used the Blast $\left(a A^{t}\right)$ line, which contains $10-20$ copies of the transgene and provides the highest levels of expression. The transgene was maintained on an F1 (C57B1/6 $\times$ CBA) genetic background and introduced onto the $m d x$ strain background by mating Blast males with $m d x$ females. The presence of the transgene was determined by Southern blotting of DNA prepared from tail biopsy samples or, in the case of embryos, from extraembryonic tissue. DNA samples were digested with $\mathrm{Xbal}$ and electrophoresed through $1 \%$ agarose gels, blotted to nylon membranes (Hybond-N, Amersham) and UVcrosslinked. These were hybridised with probes labelled to in excess of $1 \times 10^{8}$ c.p.m. $/ \mu \mathrm{g}$ by incorporation of $\left[{ }^{32} \mathrm{P}\right] \mathrm{dCTP}$ in a random hexamer-primed DNA polymerase reaction (Boehringer-Mannheim,

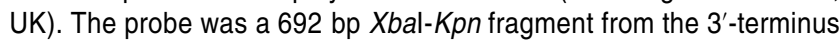
of Igf-2 exon 6 (Figure 2a). This recognises a $1.8 \mathrm{~kb}$ Xbal fragment from endogenous Igf-2 and several transgene specific bands (Figure $2 b)$. Genotyping was done independently of cell counting and the characterisation of muscle phenotype and results retained until after these had been done.

\section{Histological characterisation of phenotype}

Paraffin embedded skeletal muscle blocks prepared as above were sectioned serially onto Vectabond (Vectalabs) coated slides and scored for dystrophic morphology using standard histological protocols (as described below). Some skeletal muscle sections were also stained with haemotoxylin and eosin to gain an overall impression of the extent of their dystrophic phenotype.

Quantitative assessment of dystrophic morphology (centrally nucleated fibres, total fibre number, cellularity and fibre irregularity) was done on transverse muscle sections stained for Gill's haemotoxylin (as above). Quantitation of dystrophic histopathological features was carried out on muscle sections taken from the backcross (BC) litters. All sections were coded by a third person before counting commenced, and were not decoded until after all the data had been collected. Counting was carried out using randomly placed $(10 \times 10)$ grids as above and care was taken to ensure that cellularity, central nuclei, and fibre numbers were all derived from the same grids. Fibrosis and degeneration was assessed separately on the same muscle sections to avoid biasing data collection. Counting was done on at least 10 non-adjacent muscle sections for each animal, so that at least 3000 fibres were counted per mouse.

\section{Phenotypic characterisation by in situ hybridisation}

IGF-II mRNA localisation was carried out by DIG in situ hybridisation. ${ }^{51}$ Briefly, paraffin sections were dewaxed, rehydrated and treated with proteinase $\mathrm{K}(5 \mu \mathrm{g} / \mathrm{ml}$ in PBS, up to $30 \mathrm{~min})$ followed by brief treatment with acetic anydride $(0.75 \%)$ taking care to exclude RNAse. DIG labelled and unlabelled (cold competition controls) antisense riboprobes were prepared by T7 RNA polymerase transcription of linearised (Hincll) p28a-mouse IGF- $\|^{52}$ as described by kit instructions (Boehringer Mannheim, UK). Hybridisation was carried out on coverslipped sections at $55^{\circ} \mathrm{C}$ overnight, and followed by posthybridisation washes $(2 \times \mathrm{SSC}, 0.1 \% \mathrm{SDS} 30 \mathrm{~min}$ at room temperature, $0.1 \times \mathrm{SSC}, 01 \% \mathrm{SDS}\left(30 \mathrm{~min}\right.$ at $\left.60^{\circ} \mathrm{C}\right)$, and immunodetection with anti-digoxigenin AP fab fragments, broadly as described by the manufacturer (Boehringer Mannheim) except that antibody dilutions were determined by titration and were between 1/2000 and 1/ 8000. DIG label was visualised with alkaline phosphatase substrate (75 mg/ml 5-bromo-4-chloro-3-indoyl-phosphate (BCIP, Sigma) and $50 \mathrm{mg} / \mathrm{ml}$ nitro-blue tetrazolium (NBT, Sigma) in NMT) containing $1 \mathrm{mM}$ levamisol (Sigma) to inhibit endogenous peroxidase. All in situ experiments were set up with cold competitor controls (10:1 ratio of unlabelled to labelled antisense probe) on sections adjacent to those hybridised with labelled antisense probes.

\section{Estimation of programmed cell death}

(a) Propidium iodide or DAPI labelling was carried out on post fixed, perfused frozen muscle sections as previously described. ${ }^{13,18}$ Slides were washed in PBS and observed and counted under fluorescence illumination at $\times 40$ magnification. At least 10 nonadjacent sections were counted from each TA. Counts were expressed as either (i) per cent pyknotic nuclei of total counted or (ii) as total pyknotic cells per field, fields were placed randomly using a $10 \times 10$ grid covering an area of $0.063 \mathrm{~mm}^{2}$. In muscle sections, false positives caused by the presence of blood cells were eliminated by ex-sanguination and the cardiac perfusion of fixative. $^{13}$

(b) Acridine orange staining was also carried out as described previously. ${ }^{13}$ Trypsinised cells and cells in the medium super- 
natant were collected by centrifugation (1000 r.p.m./3 min) and then stained unfixed with acridine orange $(1 \mu \mathrm{g} / \mathrm{ml})$ for $10 \mathrm{~min}$. Stained cells were then smeared onto glass microscope slides, coverslipped and sealed with nail varnish. Frozen skeletal muscle sections were brought to room temperature and stained as for cells. Slides were then observed immediately under fluorescent light using a yellow green filter (broad FITC) and scored for pyknotic and fragmenting nuclei. Apoptotic cells are expressed as a percentage of total counted.

(c) TUNEL labelling was carried out on frozen sections and permeabilised cells using an in situ cell death kit (Boehringer Mannheim, UK, Diagnostics Biochemicals Ltd, Bell Lane, Lewes, East Sussex) and following the manufacturers instructions.

\section{Cell lines and cell culture}

$m d x$ mouse derived dystrophic skeletal muscle stem (SMS) cell lines (Dfd13 and PD50A) were derived by the authors and maintained in DF12 medium (50:50 mix of Dulbecco's minimal essential medium and Ham's F12 supplemented with glutamine and foetal calf serum) as previously described. ${ }^{45,53}$

\section{Transfection of muscle cell lines}

Dystrophic SMS cell lines (see above) were transfected with dystrophin cDNA using the construct pBSX-mda (a gift from Dr Jeff Chamberlain, Seattle, USA) which is driven from a $(6.5 \mathrm{~Kb})$ skeletal muscle specific (creatine kinase) promoter. A standard calcium phosphate protocol was used for muscle cell transfections as follows: $2 \times$ HEBS buffer (10 g/l HEPES, $16 \mathrm{~g} / \mathrm{l} \mathrm{NaCl}, 0.74 \mathrm{~g} / \mathrm{l} \mathrm{KCl}$, $0.25 \mathrm{~g} / \mathrm{l} \mathrm{Na} \mathrm{NO}_{4}$ dihydrate) was dripped into an equal volume of calcium chloride/DNA mix $\left(0.25 \mathrm{M} \mathrm{CaCl}_{2}, 100 \mu \mathrm{g} \mathrm{DNA}\right)$. Air was bubbled through the tube to aid mixing and the solution vortexed. Following precipitation at room temperature $(30 \mathrm{~min})$ the whole cocktail was added to the cells in DF12 medium (see above). After $4 \mathrm{~h}$ cells were washed with phosphate buffered saline and refed with DF12 medium. Controls were provided by parallel transfections with saline only (mock) or EF-NLS-lacZ, a CMV driven B-galactosidase construct (gift from Doug Winton, Cambridge, UK) or pGFP-tpz-CMV (Packard, UK), a CMV driven GFP construct. To provide internal confirmation of transfection success pBSX-mda was co-transfected with (1/10 volume) of the B-galactosidase or GFP constructs. Transient transfection success rates, determined by this method, were between 9 and $17 \%$. Transiently expressing cultures generated from these experiments were then assessed for PCD levels using either acridine orange or TUNEL labelling as described above. For conditioned medium (CM) experiments, $\mathrm{CM}$ from experiments described above was removed just prior to fixing at $36 \mathrm{~h}$ post transfection. $\mathrm{CM}$ was filtered $(0.2 \mu \mathrm{C})$, transferred to non-transfected cells and incubated overnight before assay for pyknotic cell death as described above.

\section{Statistical analysis}

Statistical significance of data was examined by the use of the Student's $t$-test or $\chi^{2}$ analysis as indicated in the text, or by comparison of confidence levels as previously described. ${ }^{13}$

\section{Acknowledgements}

We are grateful to Paul Schofield for discussion on aspects of this work. We thank the Wellcome Trust (grant number 040555/Z/94/Z/RB/YJ16) and the Royal Society (grant number RSRG 19484) for their support of this work. We also thank the Wellcome Trust for providing a vacation studentship grant for Rifca Le Dieu and Lorna McMillan for proofreading the final version.

\section{References}

1. Moser H (1984) Duchenne muscular dystrophy: Pathogenetic aspects and genetic prevention. Hum Genet. 66: 17-40

2. Hoffman EP, Brown RH and Kunkel LM (1987) Dystrophin: the protein product of the Duchenne muscular dystrophy locus. Cell 51:919

3. Murray JM, Davies KE, Harper PS, Meredith L, Mueller CK and Williamson R (1982) Linkage relationship of a cloned DNA sequence on the short arm of the Xchromosome to Duchenne Muscular dystrophy. Nature 300: 69-71

4. Watkins SC, Hoffman EP, Slayter HS and Kunkel LM (1988) Immunoelectron microscope localisation of dystrophin in myofibers. Nature 333: 863-866

5. Campbell KP and Kahl SD (1989) Association of dystrophin and an integral membrane glycoprotein. Nature 338: 259-261

6. Ahn AH and Kunkel LM (1995) Syntrophin binds to an alternatively spliced exon of dystrophin. J. Cell Biol. 128: 363-371

7. Campbell KP (1995) Three muscular dystrophies: Loss of cytoskeletonextracellular matrix linkage. Cell 80: 675-679

8. Brown SC and Lucy JA (1993) Dystrophin as a mechanochemical transducer in skeletal muscle. Bioessays 15: 413-419

9. Cavanna JS, Coulton G, Morgan JE, Brockdorf N, Forrest SM, Davies KE and Brown SDM (1988) Molecular and genetic mapping of the mouse mdx locus. Genomics 3: $337-341$

10. Bulfield G, Siller WG, Wight PAL and Moore KJ (1984) Chromosome X-linked muscular dystrophy in the mouse. Proc. Natl. Acad. Sci. USA 81: 1189-1192

11. Sunada Y and Campbell KP (1995) Dystrophin-glycoprotein complex: Molecular organisation and critical roles in skeletal muscle. Curr. Opin. Neurol. 8: 379-384

12. Geissinger HD, Prasada-Rao PVV and McDonald-Taylor CK (1990) ' $m d x$ ' mouse myopathy: histopathological, morphometric and histochemical observations on young mice. J. Comp. Pathol. 102: 249-263

13. Smith J, Fowke G and Schofield PN (1995) Programmed cell death in dystrophic $(m d x)$ muscle is inhibited by IGF-II. Cell Death Differ. 2: 243-251

14. Carlson CG and Makiejus RV (1990) A noninvasive procedure to detect muscle weakness in the $m d x$ mouse. Muscle Nerve 13: 480-484

15. Logan A, Smith C, Becks GP, Gonzalez AM, Phillips ID and Hill DJ (1994) Enhanced expression of transforming growth factor-betal during thyroid hyperplasia in rats. J. Endocrinol. 141: 45-57

16. Fidzianska A, Goebel HH and Warlo I (1990) Acute infantile spinal muscular atrophy: Muscle apoptosis as a proposed pathogenetic mechanism. Brain 113: $433-444$

17. Smith J (1994) Therapeutic effects of IGF-2 on dystrophic skeletal muscle. Growth Regul. 4: 61-62

18. Smith J (1996) Muscle growth factors, ubiquitin and apoptosis in dystrophic muscle: Apoptosis declines with age in the $m d x$ mouse. Basic Appl. Myol. 6: $279-284$

19. Tidball JG, Albrecht DE, Lokensgard BE and Spencer MJ (1995) Apoptosis precedes necrosis of dystrophin-deficient muscle. J. Cell Sci. 108: 2197-2204

20. Matsuda R, Nishikawa A and Tanaka H (1995) Visualisaton of dystrophic muscle fibers in $m d x$ mouse by vital staining with Evans blue: Evidence of apoptosis in dystrophic deficient muscle. J. Biochem. 118: 959-964

21. Baghdiguian S, Martin M, Richard I, Pons F, Astier C, Bourg N, Hay RT, Chemaly R, Halaby G, Loiselet J and Anderson LVB (1999) Calpain 3 deficiency is associated with myonuclear apoptosis and profound perturbation of the Ikappa $B$ alpha/NF-kappa B pathway in limb-girdle muscular dystrophy type 2A. Nature Med. 5: 503-511

22. Askanas V, Engel WK, Alvarez RB and Broccolini A (1999) Myotonic dystrophy muscle nuclei have features of apoptosis, 'apoptosis-lente', SPI accumulation and contain filamentous inclusions and ubiquitin immunoreactivity. Neurology 52: pA94

23. Mukasa T, Momoi T and Momoi MY (1999) Activation of caspase-3 apoptotic pathways in skeletal muscle fibres in laminin alpha-2 deficient mice. Biochem. Biophys. Res. Commun. 260: 139-142 
24. Hack AA, Ly CT, Jiang F, Clendenin CJ, Sigrist KS, Wollmann RL and McNally EM (1998) Gamma sarcoglycan deficiency leads to muscle membrane defects and apoptosis independent of dystrophin. J. Cell Biol. 142: 1279-1287

25. Taverna D, Disatnik MH, Rayburn H, Bronson RT, Yang J, Rando TA and Hynes RO (1998) Dystrophic muscle in mice chimeric for expression of alpha 5 integrin. J. Cell Biol. 143: 849-859

26. Stewart CEH and Rotwein $P(1996)$ Insulin-like growth factor-II is an autocrine survival factor for differentiating myoblasts. J. Biol. Chem. 271: 11330-11338

27. Harrington EA, Bennett MR, Fanidi A and Evan GI (1994) C-myc-induced apoptosis in fibroblasts is inhibited by specific cytokines. EMBO J. 13: $3286-$ 3295

28. Granerus M, Bierke P, Zumkeller W, Smith J, Engstrom W and Schofield PN (1995) Insulin-like growth factors I and II prevent apoptosis in a human teratoma derived cell line. J. Clin. Pathol.: Mol. Pathol. 48: M153-M157

29. Ward A, Bates P, Fisher R, Richardson L and Graham CF (1994) Disproportionate growth in mice with Igf-2 transgenes. Proc. Natl. Acad. Sci. USA 91: $10365-10369$

30. D'Ercole AJ and Underwood L (1980) Ontogeny of somatomedins during development in the mouse. Serum concentrations, molecular forms, binding proteins and tissue receptors. Dev. Biol. 79: 33-45

31. Da Costa THMDA, Williamson DH, Ward A, Bates P, Fisher R, Richardson L, Hil DJ, Robinson ICAF and Graham CF (1994) High Plasma insulin-like growth factor-II and low lipid content in transgenic mice: measurements of lipid metabolism. J. Endocrinol. 143: 433-439

32. Clemens PR, Kochanek S, Sunada Y, Chan S, Chen HH, Campbell KP and Caskey CT (1996) In vivo muscle gene transfer of full length dystrophin with an adenoviral vector that lacks all viral genes. Gene Ther. 3: 965-972

33. Tinsley JM and Davies KE (1993) A potential replacement for dystrophin?. Neuromus. Dis. 3: $537-539$

34. Schneider JW, Gu W, Zhu I, Mahdavi V and Nadal-Ginard B (1994) Reversal of terminal differentiation mediated by 107 in $\mathrm{Rb}-/$ - muscle cells. Science 264 : $1467-1471$

35. Zacksenhaus F, Jiang Z, Chung D, Marth JD, Phillips RA and Gallie BL (1996) pRB controls proliferation, differentiation, and death of skeletal muscle cells and other lineages during embryogenesis. Genes Dev. 10: 3051-3064

36. Emery AEH and Holloway S (1977) Use of normal daughters' and sisters' creatine kinase levels in estimating heterozygosity in Duchenne Muscular dystrophy. Hum. Hered. 27: 118-126

37. Piotrkiewicz M, Hausmanowa-Petrusewicz I and Mierzejewska J (1999) Motorneurons are altered in muscular dystrophy. J. Physiol. 93: 167-173

38. Spencer MJ, Walsh CM, Dorshkind KA, Rodriguez EM and Tidball JG (1997) Myonuclear apoptosis in dystrophic mdx muscle occurs by perforin - mediated cytotoxicity. J. Clin. Invest. 99: 2745-2751

39. Woods K, Marrone A and Smith J (2000) Programmed cell death and senescence in skeletal muscle stem cells. Ann. Acad. Sci. 908: 331-335

40. Anderson MS and Kunkel LM (1992) The molecular and biochemical basis of Duchenne muscular dystrophy. TIBS 17: 289-292
41. Pegoraro E, Schmke RN, Garcia C, Stern H, Cadaldini M, Angelini C, Barbosa E, Carroll J, Marks WA, Neville HE, Marks H, Appleton S, Torello H, Wessel HB, Donnelly J, Bernes SM, Taber JW, Weiss L and Hoffman EP (1995) Genetic and biochemical normalisation in female carriers of dystrophin production in dystrophin-competent myonuclei. Neurology 45: 677-690

42. Partridge TA, Morgan JE, Coulton GR, Hoffman EP and Kunkel LM (1989) Conversion of $m d x$ myofibers from dystrophin negative to positive by injection of normal myoblasts. Nature 337: 176-179

43. Gussoni E, Pavlath G, Lanctot AM, Sharma KR, Miller RG, Steinman L and Blau HM (1992) Normal dystrophin transcripts detected in Duchenne muscular dystrophy patients after myoblast transplantation. Nature 356: 435-438

44. Tremblay JP, Malouin F, Roy R, Huard J, Bouchard JP, Satoh A and Richards CL (1993) Results of a triple blind clinical study of myoblast transplantations without immunosuppressive treatment in young boys with Duchenne muscular dystrophy. Cell Transplant. 2: 99-112

45. Smith Jand Schofield PN (1997) Stable integration of an $m d x$ skeletal muscle cell line into dystrophic $(m d x)$ skeletal muscle: evidence for stem cell status. Cell Growth Differ. 8: 927-934

46. FeeroWG, LiS, RosenblattJD, Sirianni N, Morgan JE, Partridge TA, Huang L and Hoffman EP (1997) Selection and use of ligands for receptor-mediated gene delivery to myogenic cells. Gene Ther. 4: 664-674

47. Larochelle N, Lochmuller H, Zhao J, Jani A, Hallauer P, Hastings KEM, Massie B, Prescott S, Petrof BJ, Karpati G and Nalbantoglu J (1997) Efficient musclespecific transgene expression after adenovirus-mediated gene transfer in mice using a 1.35 kb muscle creatine kinase promoter/enhancer. Gene Ther. 4:465472

48. Dennis CL, Tinsley JM, Deoninck AE and Davies KE (1996) Molecular and functional analysis of the utrophin promoter. Nucl. Acids. Res. 24: 1646-1652

49. Tinsley JM, Potter AC, Phelps SR, Fisher R, Trickett JI and Davies KE (1996) Amelioration of the dystrophic phenotype of $m d x$ mice using a truncated utrophin transgene. Nature 384: 349-353

50. Grammolini AO, Angus LM, Schaeffer L, Burton EA, Tinsley JM, Davies KE, Changeux JP and Jasmin BJ (1999) Induction of utrophin gene expression by heregulin in skeletal muscle cells role of the $\mathrm{N}$-box motif and $\mathrm{GA}$ binding protein. Proc. Natl. Acad. Sci. USA 96: 3223-3227

51. Wilkinson DG (1992) Whole mount in situhybridisation of vertebrate embryos. In: in situ hybridisation: A practical approach. Wilkinson DG, ed (Oxford: IRL Press) pp. $75-83$

52. Stempien MM, Fong NM, Rall IB and Bell GI (1986) Sequence of a placental cDNA encoding the mouse insulin-like growth factor II precursor. DNA 5: 357 361

53. Smith J and Schofield PN (1994) The effects of fibroblast growth factors in long term primary culture of dystrophic (mdx) mouse muscle myoblasts. Expl. Cell Res. 210: 86-93

54. Rotwein P and Hall LJ (1990) Evolution of insulin-like growth factor II: characterization of the mouse IGF-II gene and identification of two pseuobexons. DNA Cell Biol. 10: 725-735 